\title{
Immunization coverage and its associated factors among children residing in project affected population's resettlement colonies in urban slum of Mumbai, Maharashtra, India
}

\author{
Naresh Gill ${ }^{1}$, Ravikant Singh ${ }^{2}$, Aniket Mondal ${ }^{3}$, Balaram Jadhav ${ }^{4}$
}

\author{
${ }^{1}$ Department Community Medicine, D.Y. Patil Medical College, Kolhapur, Maharashtra, India \\ ${ }^{2}$ Doctors for You, Mumbai, Maharashtra, India \\ ${ }^{3}$ Doctors for You, MRVC Health Centre, Bldg no-22, Maharashtra, India \\ ${ }^{4}$ Public Health Consultant, Doctors for You, Hiranandani, Lallubhai Compound, Mankhurd, Mumbai, India
}

Received: 10 May 2016

Accepted: 04 June 2016

\author{
*Correspondence: \\ Dr. Balaram Jadhav, \\ E-mail: drbalaram.dfy@gmail.com
}

Copyright: () the author(s), publisher and licensee Medip Academy. This is an open-access article distributed under the terms of the Creative Commons Attribution Non-Commercial License, which permits unrestricted non-commercial use, distribution, and reproduction in any medium, provided the original work is properly cited.

\section{ABSTRACT}

Background: With the rapid urbanization and numerous infrastructure projects going on in cities, large number populations are affected by these development projects. Such Projects Affected People (PAP) is resettled in colonies where critical health services are often lacking. Immunization is one such preventive and promotive health services, which is often cited as one of the greatest public health achievement of $20^{\text {th }}$ century and has resulted in dramatic decrease in morbidity and mortality due to vaccine preventable diseases. However, effective protection against these vaccine preventable diseases requires $90-95 \%$ immunization coverage. This study was conducted to assess the immunization coverage in PAP resettlement area of urban slum in Mumbai and associated responsible factors.

Methods: Immunization coverage was assessed with the help of the WHO's 30cluster sampling method with a sample size of 210 children in the 12-23 months age group.

Results: $90 \%$ children were completely immunized. The immunization coverage was highest for BCG (98.1\%) and least for measles $(90 \%)$. The most common reason for noncompliance was child's illness at the time of scheduled vaccine dose.

Conclusions: The Universal Immunization Programme (UIP) goal of $85 \%$ immunization coverage can be achieved by community based awareness activities, supplemented by patient friendly immunization services at the health centre.

Keywords: Primary immunization, PAP, Universal immunization program, WHO's 30 cluster sampling

\section{INTRODUCTION}

With rapid urbanization and large-scale development activities going on in Indian cities, a large population is displaced, which need to be resettled. Although shelter is provided, but the Project Affected People (PAP) are often neglected, they don't have access to promotive and preventive health services such as immunization, family planning services and general health checkup. This is the cost of development; such displaced groups have to pay. Immunization is often cited as being one of the greatest public health achievements of the $20^{\text {th }}$ century which has resulted in dramatic decrease in morbidity and mortality due to vaccine preventable diseases. ${ }^{1}$

However, effective protection against these diseases requires $90-95 \%$ immunization coverage. ${ }^{2}$ Immunization coverage refers to information on the proportion of children who have received specific vaccines or are up to date with the recommended vaccine schedule. This information is essential for planning immunization programs, identifying the vulnerable groups that require 
targeting with increased resources, assessing the acceptability of a program and predicting likely vaccine preventable disease epidemics. ${ }^{2}$ A child is considered fully immunized if $\mathrm{s} / \mathrm{he}$ has received $\mathrm{BCG}$; Bacillus Calmette Guerin (BCG) vaccine, three doses of Diptheria, Pertussis, and Tetanus Vaccine (DPT), Oral Polio Vaccine (OPV), Hepatitis B and measles. Despite the Universal Immunization Program (UIP) run by GOI, being functional since 20 years, the national coverage has not crosses $50 \%$ mark. $^{3}$

In India, only $44 \%$ of children aged $12-23$ months are fully vaccinated (NFHS-3), which is marginally better than $42 \%$ during NFHS-2. ${ }^{3}$ The coverage is also not uniform for all the vaccines like coverage is highest for Polio Vaccines followed by DPT and HBV. The vaccine coverage is likely to be lower in various pockets of susceptible populations like slums, street children, children from resettlement colonies etc. ${ }^{4}$ It is therefore necessary to know if low vaccine coverage is a problem in specific vulnerable population groups. Thus the present study was carried to assess the primary immunization coverage in project affected people's (PAP's) resettlement colonies in urban slums of Mumbai.

Aim of the study was to assess the immunization coverage in PAP's resettlement colonies in urban slums of Mumbai and determine the various socio-demographic factors affecting the same. And the objectives of the study were to assess immunization coverage for individual vaccines among children aged 12-23 months, to identify socio demographic factors associated with non-compliance

\section{METHODS}

The present community based descriptive study was carried out in PAP's resettlement colonies in the Lallubhai compound, Mankhurd, Mumbai, Maharashtra, India. The health services in this area are mainly provided by a NGO, Doctors for You (DFY), an comprehensive various public health interventions through an health Centre in the area. Immunization services to provide immunity against 7 vaccine preventable diseases (tuberculosis, polio, diptheria, pertusis, tetanus, hepatitis $\mathrm{B}$ and Measles) are carried out twice a week at the health centre.

The services at the health centre are supplemented by outreach services such health and immunization camps in the area. The approximate population of this area is 56,200 . The area is divided in 84 natural clusters in form of 5 and 7 stories buildings with each building having 120 and 144 families respectively. And study was conducted from July 2014 to September 2014 (3 months).The study populations comprised children aged 12-23 months. Age was confirmed by birth certificates or immunization cards or when it was not available, by asking the mothers (Using the standard Indian calendar and major holidays as reference points).

\section{Complete immunization}

Children have received BCG, three doses of OPV, DPT, HBV each and Measles.

\section{Partial/incomplete immunization}

Children who are not completely immunized but have at least received one dose of any above mentioned vaccines.

\section{Unimmunized children}

Children who have not received a single dose of any vaccine (pulse polio OPV is excluded).

The WHO's 30 cluster sampling method was used for evaluation of immunization coverage. ${ }^{5}$ Among the 84 natural clusters (5 and 7 story buildings) 30 buildings were randomly selected. Seven children between 12-23 months of age were selected from each of 30 clusters, with the effective sample size being 210 children. After getting the list of building to be covered, the floor from which the first child has to be taken was randomly selected and every next house was studied in a sequence, until a total size of seven eligible children in the age group 12-23 months were covered.

On reaching the selected household, the mother or care giver of the eligible child was interviewed. If no child belonging to the target population was found, next household was checked. If there were twins in the target population, both were included in the study. Preformed, pretested, semi structured questionnaire was used to collect the information from mothers regarding socio demographic parameters, immunization coverage and reasons for non-compliances, if any. The immunization coverage was assessed on following aspects

- Availability of Immunization card

- BCG mark/scar

- Immunization history checked from the card or elicited carefully from the mother or caregiver.

While conducting the study Declaration Helsinki guidelines were followed. Verbal consent was obtained from the mothers or caregivers before collecting the information. Statistical Analysis: The information was entered in Microsoft Excel 2007 and analyzed with the help of statistical software SPSS version 16.

\section{RESULTS}

In the study female to male ratio was almost $1: 1.97 .1 \%$ of children were delivered at hospital. Majority of the families belong to middle and lower class as per modified Prasad's classification, while $20 \%$ respondents choose not to disclose the income (Table 1). 
Table 1: Demographic profile of study participants.

\begin{tabular}{|c|c|c|c|}
\hline Variable & & Frequency & Percent \\
\hline \multirow{2}{*}{ Gender } & Male & 101 & 48.1 \\
\hline & Female & 109 & 51.9 \\
\hline \multirow{3}{*}{ Birth order } & 1 & 78 & 37.1 \\
\hline & 2 & 89 & 42.4 \\
\hline & $\geq 3$ & 43 & 20.5 \\
\hline \multirow{2}{*}{ Place of delivery } & Home & 6 & 2.9 \\
\hline & Hospital & 204 & 97.1 \\
\hline \multirow{5}{*}{$\begin{array}{l}\text { Mother's } \\
\text { Education }\end{array}$} & Graduate & 17 & 8.1 \\
\hline & HSC & 34 & 16.2 \\
\hline & SSC & 24 & 11.4 \\
\hline & Primary & 84 & 40.0 \\
\hline & Illiterate & 51 & 24.3 \\
\hline \multirow{6}{*}{$\begin{array}{l}\text { Socio Economic } \\
\text { Status (Modified } \\
\text { Prasad's } \\
\text { Classification) }^{15}\end{array}$} & I & 3 & 1.4 \\
\hline & II & 37 & 17.6 \\
\hline & III & 65 & 31.0 \\
\hline & IV & 54 & 25.7 \\
\hline & $\mathrm{V}$ & 9 & 4.3 \\
\hline & NA & 42 & 20.0 \\
\hline
\end{tabular}

Study finding revealed that $90 \%$ of children were completely immunized while only $1.43 \%$ children had not received any vaccination (Table 3 ). On assessing individual vaccines, the coverage of BCG was found to be highest (206 out of $210,98.1 \%$ ).
Table 2: Immunization coverage.

\begin{tabular}{|lcl|}
\hline Vaccine doses & Frequency & Percent \\
\hline BCG & 206 & 98.1 \\
\hline 1st Dose (OPV1,DPT1, HBV1) & 204 & 97.1 \\
\hline $2^{\text {nd }}$ Dose (OPV2, DPT2, HBV2) & 201 & 95.7 \\
\hline $3^{\text {rd }}$ dose (OPV3, DPT3, HBV3) & 200 & 95.2 \\
\hline Measles & 189 & 90.0 \\
\hline
\end{tabular}

Table 3: immunization status of study participants.

\begin{tabular}{|llll|}
\hline Variable & & Frequency & Percent \\
\hline Immunization & Yes & 200 & 95.2 \\
\cline { 2 - 4 } Card & No & 10 & 4.8 \\
\hline \multirow{2}{*}{ BCG Mark } & Yes & 196 & 93.3 \\
\cline { 2 - 4 } & No & 14 & 6.7 \\
\hline \multirow{2}{*}{$\begin{array}{l}\text { Immunization } \\
\text { Status }\end{array}$} & Complete & 189 & 90.0 \\
\cline { 2 - 4 } & Partial & 18 & 8.6 \\
\cline { 2 - 4 } & Unimmunized & 3 & 1.4 \\
\hline
\end{tabular}

The immunization coverage for $1^{\text {st }}, 2^{\text {nd }}$ and $3^{\text {rd }}$ doses of DPT, OPV and HBV was $97.1 \%, 95.7 \%$ and $95.2 \%$ respectively (Table 2). The coverage of measles was lowest among all the vaccines $(90 \%)$. BCG mark was present in $95.14 \%$ children, who received the BCG vaccine. Immunization card was there with $95.2 \%$ beneficiaries (Table 3).

Table 4: Socio-demographic factors affecting immunization coverage.

\begin{tabular}{|c|c|c|c|c|c|}
\hline Variable & & Group frequency & Complete & Partial/Unimmunized & P Value \\
\hline \multirow[b]{2}{*}{ Sex } & Male & 109 & 98 & 11 & \multirow{2}{*}{1} \\
\hline & Female & 101 & 91 & 10 & \\
\hline \multirow{3}{*}{ Birth order } & 1 & 78 & 72 & 6 & \multirow{3}{*}{0.546} \\
\hline & 2 & 899 & 80 & 9 & \\
\hline & $\geq 3$ & 43 & 37 & 6 & \\
\hline \multirow{2}{*}{ Place of delivery } & Home & 6 & 4 & 2 & \multirow{2}{*}{0.112} \\
\hline & Hospital & 204 & 185 & 19 & \\
\hline \multirow{4}{*}{ Mother education } & Illiterate & 51 & 44 & 7 & \multirow{4}{*}{0.583} \\
\hline & Primary & 84 & 75 & 9 & \\
\hline & SSC & 24 & 22 & 2 & \\
\hline & HSC \& Grad & 51 & 48 & 3 & \\
\hline \multirow{3}{*}{ Family size } & $\leq 5$ & 93 & 83 & 10 & \multirow{3}{*}{0.674} \\
\hline & $>5$ to 8 & 87 & 80 & 7 & \\
\hline & $>8$ & 30 & 26 & 4 & \\
\hline \multirow{2}{*}{ Card } & Yes & 200 & 188 & 12 & \multirow{2}{*}{$<0.001$} \\
\hline & No & 10 & 1 & 9 & \\
\hline \multirow{4}{*}{ SES } & Upper (I \&II) & 40 & 38 & 2 & \multirow{4}{*}{0.011} \\
\hline & Middle (III) & 65 & 63 & 2 & \\
\hline & Lower (IV \&V) & 63 & 55 & 8 & \\
\hline & NA & 42 & 33 & 9 & \\
\hline
\end{tabular}


The main reason for noncompliance was child's illness at the time of scheduled vaccinations followed by loss of immunization card (Table 4). On assessing various demographic factors it was low in children with birth order 3 or more, lower education of mother, lower socioeconomic condition and loss of immunization card (Table 5).

\section{Table 5: Reasons for partial immunization or Un-} immunization $(n=21)$.

\begin{tabular}{|lll|}
\hline Reasons & Frequency & Percent \\
\hline Child's illness & 10 & 47.6 \\
\hline Loss of card & 4 & 19.0 \\
\hline Being busy in other works & 2 & 9.5 \\
\hline $\begin{array}{l}\text { No one to accompany the } \\
\text { mother \& child }\end{array}$ & 2 & 9.5 \\
\hline $\begin{array}{l}\text { Gone to native place at the } \\
\text { time scheduled dose }\end{array}$ & 1 & 4.8 \\
\hline Change of house & 1 & 4.8 \\
\hline $\begin{array}{l}\text { Not aware about } \\
\text { immunization }\end{array}$ & 1 & 4.8 \\
\hline
\end{tabular}

\section{DISCUSSION}

The present study conducted in the Project affected People's resettlement colonies showed $90 \%$ primary immunization coverage, which is more than the national average $43.5 \%$ NFHS 3 and $70 \%$ immunization coverage in the state of Maharashtra. ${ }^{6}$ The overall coverage for different vaccines ranges from $98.1 \%$ BCG to $90 \%$ for measles, which was above the $85 \%$ target set by universal immunization programme (UIP) in India.

In the unpublished data of base line survey conducted by doctors for you (NGO) at the start of project, only $59 \%$ children from 12-23 months age group were completely immunized. The immunization coverage was found to be the highest for BCG $(87.6 \%)$ followed by $78 / 6 \%$ for $1^{\text {st }}$ dose, $76.2 \%$ for $2^{\text {nd }}$ dose, $66.7 \%$ for $3^{\text {rd }}$ dose and $62.4 \%$ for measles.

In a study Kadri et al in Ahemdabad slums recorded $83.3 \%$ coverage for BCG and $71.7 \%$ for measles, in this study, only $70.3 \%$ children were completely immunized. ${ }^{7}$ Singh et al on Immunization status of India showed BCG and measles coverage of $86 \%$ and $67 \%$ respectively. ${ }^{8}$ Similar results were found by Yadav et al in an urban slum of Jamnagar where BCG coverage was maximum $(94.7 \%)$ followed by OPV $(84.7 \%)$ and DPT $(81.4 \%)$ and that of measles was least $(75.7 \%){ }^{9}$

In a study on malnutrition and immunization coverage in Rafiq Nagar, Mumbai, the nearest slum to the study area by Bhavsar $\mathrm{S}$ et al, complete immunization coverage was just $46.4 \%$, highest coverage was noted for BCG $(90.7 \%)$ followed by $88.1 \%$ for first dose of OPV, DPT and HBV each, $77.3 \%$ for second dose and $63.9 \%$ for third dose. ${ }^{10}$ The least immunization coverage was noted for measles
(52.1\%). In this study, OPV doses given during pulse polio were not included in the assessment of immunization coverage.

The most common reason for not immunizing the child as cited by respondents were illness of the child (47.6\%), loss of card $(19 \%)$, being busy in other work $(9.5 \%)$. Unawareness about immunization programme was seen in only one respondent. A study conducted by Kar et al showed that the major causes of incomplete immunization were illness of child $(30.8 \%)$, unawareness $(23.1 \%)$ and migration to native place $(23.1 \%) .{ }^{11}$ Another similar study by Nath et al showed visit to native place (14.7\%), sickness of child (11.7\%) and lack of knowledge $(10.4 \%)$ were main reasons for incomplete immunization. $^{12}$

Immunization status was found to be significantly low among lower socio economic group, those who did not responded and were not having card. Although not significant but it was low if mother was illiterate or educated up to primary only, higher birth order and home delivery. A study done by Vikram et al found association between mother's education and immunization status. ${ }^{13} \mathrm{~A}$ study in urban slums of Lucknow by Nath et al found that children born at home are less likely to complete vaccination. ${ }^{12}$ Studies done by Bobo et al and Brenner et al revealed that birth order was inversely related to vaccination coverage. ${ }^{14,15}$

\section{Recommendations}

The improvement in immunization coverage from baseline complete primary immunization coverage of $59 \%$ to $90 \%$ in Project Affected People's resettlement colonies in urban slums of Mumbai can be attributed to the strategic approach of the NGO, doctors for you, towards achieving universal primary immunization coverage in children. The activities carries out were as follows-

- Survey of beneficiaries in the community and awareness about importance of immunization

- Immunization camps in the area for the identified beneficiaries supplemented by immunization on fixed days at the health centre.

- Incentives to the beneficiaries at the time of vaccination and after complete immunization.

- Making immunization card counterfoil and then following up by home visits for drop outs.

- Issuing duplicate immunization card, if original one is misplaced by any reason.

The success of these strategies is evident by high immunization coverage and low level of unawareness (1 out of $210,0.47 \%$ ). At Government health facilities, the mother or care giver is severely reprimanded on misplacing the cards, which deters such population to utilize services. 
For population in transitions, losing their important records can occur many times, in such conditions, issuing a fresh immunization card will not deter the mothers from utilizing immunization services. At the same time, giving some incentives i.e. soap or tooth paste (mobilized from corporate social responsibility fund or local funds) will help in success of achieving universal immunization coverage and lowering morbidity and mortality due to vaccine preventable diseases.

\section{CONCLUSION}

The Universal Immunization Programme (UIP) goal of $85 \%$ immunization coverage can be achieved by community based awareness activities, supplemented by patient friendly immunization services at the health center, along with planned surveys, providing and partnering outreach immunization services and motivation of mothers through incentives.

\section{ACKNOWLEDGEMENTS}

The authors would like to acknowledge the great help they received from the scholars whose articles are cited and included in references of this paper. The authors are also grateful to authors/editors/publishers of all those articles, journals and books from where the literature for this paper has been reviewed and discussed.

\section{Funding: No funding sources}

Conflict of interest: None declared

Ethical approval: The study was approved by the Institutional Ethics Committee

\section{REFERENCES}

1. CDC. Ten great public health achievement-United States, 1900-1999. Morbidity and Mortality Weekly Report. 1999;48:241-3,.

2. Ministry of Health, The National Childhood Immunisation Coverage Survey 2005, Ministry of Health, Wellington, New Zealand, 2007.

3. Ministry of Health and family welfare government of India, "Introduction, Child Health, Maternal Health," in National Family Health Survey (NFHSIII). Volume I, International Institute for Population Sciences Publishers, 2005-2006

4. Mathew JL. Inequity in childhood immunization in India: a systematic review." Indian pediatrics. 2012;49(3):203-23.
5. The module for mid-level for managers: the EPI coverage survey WHO/IV B/08.07. 2008, http://www.who.int/ immunization/ documents/ $\mathrm{mlm} / \mathrm{en} /$ index.html.

6. Sharma S. Immunization coverage in india, institute of economic growth, university enclave, New Delhi, India. http://www.iegindia.org/ workpap/ wp283.pdf.

7. Kadri AM, Singh A, Jain S, Mahajan RG, Trivedi A. Study on immunization coverage in urban slums of Ahemdabad City. Health and population: Perspectives and Issues. 2010;33(1):50-4.

8. Singh P, Yadav RJ. Immunization status of children of India. Indian Pediatrics. 2000;37:1194-9.

9. Yadav S, Mangal S, Padhiyar N, Mehta JP, Yadav BS. Evaluation of immunization coverage in urban slums of Jamnagar city. Indian Journal of Community Medicine. 2006;31(4).

10. Bhavsar S, Mahajan H, Kulkarni R. Assessment of the nutritional status and immunization coverage of Anganwadi children in Rafiq nagar Mumbai. Public Health Research. 2012;2(6):229-34.

11. Kar M, Reddaiah VP, Kant S. Primary immunization status of children in slum areas of South Delhi. Indian Journal of Community Medicine. 2001;26(3)161.

12. Nath B, Singh J, Awasthi S, Bhushan V, Kumar V, Singh S. A study on determinants of immunization coverage among 12-23 months old children in urban slums of Lucknow district, India. Indian Journal of Medical Sciences. 2007;61(11):598-606.

13. Vikram K. Linkage between maternal education and childhood immunization in India, Soc Sci Med. 2012;75(2):331-39.

14. Bobo JK, Gale JL, Thapa PB, Wassilak SGF. Risk factors for delayed immunization in a random sample of 1163 children from Oregon and Washington," Pediatrics. 1993;91(2):308-14.

15. Brenner RA, Simons-Morton BG, Bhaskar B, Das A, Clemens JD. "Prevalence and predictors of immunization among inner-city infants: a birth cohort study," Pediatrics. 2001;108(3):661-70.

Cite this article as: Gill N, Singh R, Mondal A, Balaram J. Immunization coverage and its associated factors among children residing in project affected population's resettlement colonies in urban slum of Mumbai, Maharashtra, India. Int J Community Med Public Health 2016;3:1783-7. 